\title{
PENGEMBANGAN APLIKASI BERBASIS SMARTPHONE PENDETEKSI DINI PADA MANAJEMEN KETAHANAN PANGAN DI INDONESIA
}

(Smartphone-Based Application Development of Detectors in

Food Security Management in Indonesia)

\author{
Almira Ajeng Pangestika1, Ari Rismansyah², Muarrikh Yazka Ginang ${ }^{3}$, Budiasih ${ }^{4}$ \\ Politeknik Statistika STIS ${ }^{1}$ \\ Politeknik Statistika STIS ${ }^{2}$ \\ Politeknik Statistika STIS ${ }^{3}$ \\ Politeknik Statistika STIS ${ }^{4}$ \\ Jl. Otto Iskandardinata No. 64C,Jakarta Timur, DKI Jakarta, Indonesia \\ E-mail: 15.8491@stis.ac.id
}

\begin{abstract}
ABSTRAK
Salah satu indikator yang belum tercapai tersebut adalah indikator gizi dan asupan kalori yang tercantum dalam tujuan pertama MDGs (menanggulangi kelaparan dan kemiskinan) atau tujuan ke-2 SDGs yaitu memberantas kelaparan. Negara-negara berkembang dituntut untuk lebih konsepsional dan menggunakan data ilmiah dalam menyusun kebijakan dan program gizi. Upaya memantapkan ketahanan pangan di Indonesia bahkan menjadi prioritas utama pembangunan karena hal tersebut penting kaitannya dengan kualitas sumber daya yang akhirnya diharapkan dapat menurunkan angka kemiskinan. Penelitian ini menggunakan back propagation neural network untuk deteksi dini pada manajemen ketahanan pangan di Indonesia sehingga dapat mempermudah pemerintah dalam merumuskan rencana dan kebijakan yang berkaitan dengan ketahanan pangan nasional. Hasil yang diperoleh adalah model back propagation neural network yang digunakan untuk memprediksi kelompok prioritas kerawanan pangan di setiap provinsi memiliki tingkat akurasi sebesar 0,902 (sangat baik). Implementasi selanjutnya adalah membangun aplikasi berbasis android untuk mendeteksi ketahanan pangan masing-masing wilayah sehingga dapat membantu mengefektifkan penyebaran informasi dan pengetahuan mengenai ketahanan pangan setiap wilayah serta faktor-faktor yang mempengaruhi ketahanan pangan.
\end{abstract}

Kata kunci: back propagation neural network, deteksi dini, Indonesia, ketahanan pangan

\section{ABSTRACT}

One indicator which hasn't been achieved yet is the nutrition and calorie intake indicators listed in the first goal of the MDGs (to eradicate extreme poverty and hunger) or the second goal of the SDGs (zero hunger). Developing countries are required to be more conceptual and to use scientific data to develop nutrition policies and programs. Efforts to strengthen food security in Indonesia becomes top development priority because it is important in relation to the resources quality, which is ultimately expected to reduce poverty. This study uses back propagation neural networks for early detection of food security management in Indonesia so it can facilitate the government to make best plans and policies related to national food security. The result obtained is back propagation neural network model used to predict priority groups for food insecurity in each province has an accuracy level of 0.902 (very good). The next implementation is to build an Android-based application to detect food security so it can help to disseminate information and knowledge effectively about food security in each region and its factors that affect it.

Keywords: back propagation neural network, early detection, Indonesia, food security

\section{PENDAHULUAN}

Capaian Indonesia terkait Millennium Development Goals (MDGS) yang sebelumnya diterapkan dalam sebagai landasan kebijakan bagi seluruh Negara di dunia, khususnya di Indonesia, belum sepenuhnya mencapai target tujuan yang memuaskan. Hal tersebut mengingat dari 8 tujuan, 18 target dan 67 indikator MDGs, sebanyak 18 indikatornya belum tercapai. Adanya pelaksanaan pembangunan yang belum terselesaikan tersebut membuat Sustainable Development Goals (SDGs) kemudian menjadi 
agenda pembangunan selanjutnya dari MDGs. Dimensi yang menjadi prinsip universal dalam SDGs merupakan dimensi yang memiliki keterlibatan aktif. Kerangka kerja yang dimiliki SDGs merupakan kerangka yang komprehensif, terintegrasi dan tidak terpisahkan. Hal tersebut dibuktikan dengan banyaknya tujuan dari SDGs yang lebih banyak, kompleks dan menyeluruh yaitu 17 tujuan, 169 target dan 241 indikator.

Salah satu indikator yang belum tercapai tersebut adalah indikator gizi dan asupan kalori yang tercantum dalam tujuan pertama MDGs (menanggulangi kelaparan dan kemiskinan) (Bappenas, 2017). Selanjutnya, hal tersebut diteruskan pada tujuan ke-2 SDGs yaitu memberantas kelaparan. Hal tersebut dikarenakan permasalahan kelaparan dan kekurangan gizi di Afrika dan Asia masih menjadi permasalahan yang selalu disorot sehingga mendorong lembaga gizi Perserikatan Bangsa-Bangsa (PBB) menganjurkan negara-negara berkembang lebih konsepsional dan menggunakan data ilmiah dalam menyusun kebijakan dan program gizi (Purwantini, 2014).

Upaya memantapkan ketahanan pangan di Indonesia merupakan prioritas utama pembangunan karena hal tersebut penting kaitannya dengan kualitas sumber daya yang akhirnya diharapkan dapat menurunkan angka kemiskinan. Seperti yang tertulis dalam UU No 18 Tahun 2012 tentang Pangan menyebutkan bahwa pemerintah berkewajiban mengelola stabilisasi pasokan dan harga pangan pokok, mengelola cadangan pangan pokok pemerintah, dan distribusi pangan pokok untuk mewujudkan kecukupan pangan pokok yang aman dan bergizi bagi masyarakat. Peningkatan kualitas sumber daya manusia karena tercapainya ketahanan pangan masyarakatnya menjadi salah satu alasan pemicu peningkatan produktivitas yang pada akhirnya dapat meningkatkan daya saing untuk memperbaiki status sosial ekonomi masyarakat (Kemenko, 2012). Untuk mencapai hal tersebut diperlukan perencanaan matang serta data dan informasi penunjang yang cukup karena ketahanan pangan tidak sebatas pada kecukupan persediaan pangan namun akses pangan dan pemanfaatan pangan.

Sayangnya, kebijakan yang berkaitan tentang ketahanan panggan di Indonesia belum didukung oleh sistem yang dibangun untuk mendeteksi terjadinya penurunan ketahanan pangan di suatu daerah. Padahal perkembangan teknologi yang semakin pesat dimungkinkan untuk dibangunnya sistem untuk melakukan deteksi dini pada peristiwa penurunan ketahanan pangan di suatu daerah. Oleh karena itu, penelitian ini bertujuan untuk melakukan deteksi dini pada manajemen ketahanan pangan di Indonesia menggunakan back propagation neural network. Penelitian ini bertujuan untuk mempermudah pemerintah dalam merumuskan rencana dan kebijakan yang berkaitan dengan ketahanan pangan nasional. Hasil dari penelitian ini diharapkan dapat digunakan sebagai bahan pertimbangan pemerintah dalam melakukan upaya pencegahan dan penanganan terhadap masalah ketahanan pangan di Indonesia.

\section{METODE}

Berdasarkan Food Insecurity Atlas Indonesia 2005 untuk mengetahui kondisi krisis pangan suatu daerah dapat dilihat dari indeks ketahanan pangan. Terdapat beberapa indikator yang diperlukan untuk menghitung indeks ketahanan pangan. Adapun sumber data yang digunakan adalah berasal dari Badan Pusat Statistik, Badan Ketahanan Pangan, Dinas Kehutanan, Departemen Pekerjaan Umum dan Badan Meteorologi Geofisika. Berikut disajikan indikator yang digunakan dalam menghitung indeks ketahanan pangan.

Tabel 1. Indikator ketahanan pangan

\begin{tabular}{|c|c|c|}
\hline No & Variabel & Indikator \\
\hline (1) & $(2)$ & (3) \\
\hline 1. & Ketersediaan Pangan & Rasio Konsumsi Normatif \\
\hline \multirow{3}{*}{2.} & \multirow{3}{*}{$\begin{array}{l}\text { Akses Pangan dan } \\
\text { Pencaharian }\end{array}$} & Persentasi penduduk hidup di bawah garis kemiskinan \\
\hline & & $\begin{array}{l}\text { Persentasi desa yang tidak memiliki akses penghubung yang } \\
\text { memadai }\end{array}$ \\
\hline & & Persentasi penduduk tanpa akses listrik \\
\hline \multirow{3}{*}{3} & \multirow{3}{*}{ Kesehatan dan Gizi } & Angka harapan hidup pada saat lahir \\
\hline & & Berat badan balita di bawah standard \\
\hline & & Perempuan Buta Huruf \\
\hline
\end{tabular}




\begin{tabular}{|l|l|l|}
\hline \multirow{2}{*}{4.} & Angka Kematian Bayi \\
\cline { 3 - 3 } & \multirow{4}{*}{ Kerawanan Pangan Sementara } & Penduduk tanpa akses ke air bersih \\
\cline { 3 - 3 } & & Persentasi penduduk yang tinggal lebih dari $5 \mathrm{~km}$ dari puskesmas \\
\cline { 3 - 3 } & & Persentasi daerah berhutan \\
\cline { 3 - 3 } & & Persentasi daerah puso \\
\cline { 3 - 3 } & Daerah rawan longsong dan banjir \\
\cline { 3 - 3 } & Penyimpangan Curah Hujan \\
\hline
\end{tabular}

Sumber: Food Insecurity Atlas Indonesia 2005

Data yang digunakan dalam penelitian ini memuat 8 (delapan) indikator (terlampir) yang digunakan dalam menghitung klasifikasi prioritas kerawanan pangan dari kabupaten dan kota di Indonesia serta memuat label prioritas kerawanan pangan yang bernilai satu (sangat buruk) sampai enam (sangat baik). Adapun metode analisis yang digunakan adalah back propagation neural network menggunakan Phyton dalam melakukan preprocessing serta pembangunan model.

\section{HASIL DAN PEMBAHASAN}

Pengentasan kelaparan, ketahanan pangan, dan kedaulatan pangan menjadi hal krusial bagi Negara di seluruh dunia khususnya di Indonesia yang dikenal sebagai negera dengan sumber daya alam melimpah dan beraneka ragam. Selain itu, berdasarkan data Supas (Survei Penduduk Antar Sensus) 2015, Indonesia juga dikenal sebagai Negara pemilik sumber daya manusia yang banyak dengan proyeksi mencapai 266,91 juta jiwa pada tahun 2019. Sayangnya, jumlah tersebut tidak diimbangi dengan peningkatan produksi pangan (Dharmawan, 2016). Hal itu membuat Indonesia dihadapi masalah besar untuk memenuhi kebutuhan pangan nasional.

\section{Rasio Konsumsi Normatif terhadap Produksi Bersih per Kapita}

Rasio konsumsi normatif adalah perbandingan antara total konsumsi dan produksi yang menunjukkan tingkat ketersediaan pangan di suatu wilayah. Rasio konsumsi normatif perkapita terhadap produksi pangan merupakan salah satu indikator ketersediaan pangan yang digunakan dalam analisis ketahanan pangan. Nilai rasio konsumsi normatif terhadap produksi bersih per kapita adalah sangat timpang antar provinsi. Hal tersebut dapat dilihat untuk provinsi Kepulauan Riau yang memiliki 16,35 persen rasio konsumsi normative dan hanya sebesar 0,15 persen saja rasio konsumsi di provinsi Lampung. Apabila dilihat berdasarkan ketersediaan makanan, provinsi Kepulauan Riau memegang nilai tertinggi. Nilai rasio konsumsi normative tersebut yang berjumlah lebih dari 1 (satu) menandakan bahwa total konsumsi lebih besar dibandingkan produksi.

Besar persentase rasio konsumsi normative terbesar yang dimiliki oleh Kepulauan Riau artinya konsumsi masyarakatnya cenderung tinggi, nemun keinginan untuk memproduksi masih lebih sedikit dibandingkan tingkat konsumsinya. Meskipun begitu, untuk produksi komoditi seperti gandum/sereal, provinsi Kepulauan Riau menjadi provinsi dengan produksi komoditi tersbesar. Sementara itu daerah penghasil utama produksi beras yaitu Lampung memiliki rasio konsumsi normative yang sangat kecil (kurang dari 0). Hal tersebut menandakan produksi pangan di daerah tersebut adalah sangat baik dan cukup. 


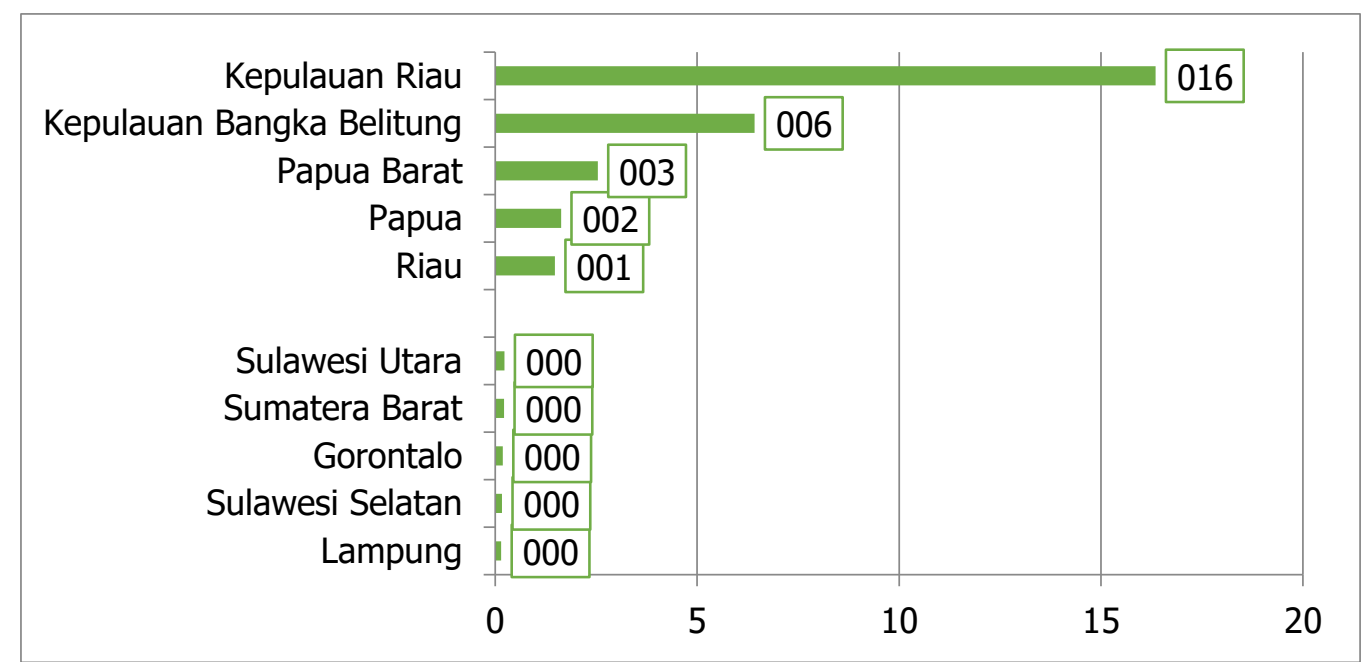

Gambar 1. Rasio konsumsi normatif terhadap produksi bersih per kapita untuk lima provinsi terbesar dan terkecil, Tahun 2015.

\section{Persentase Penduduk Dibawah Garis Kemiskinan}

Penduduk miskin adalah penduduk yang memiliki rata-rata pengeluaran per kapita per bulan di bawah Garis Kemiskinan. Penduduk miskin karena pendapatannya yang kurang, akhirnya membuat rumah tangga tersebut tidak mampu memberi pangan yang bergizi dan mencukupi agar dapat hidup sehat dan produktif (Widayaningsih, 2012). Provinsi Papua adalah provinsi dengan persentase penduduk dibawah garis kemiskinan terbanyak yaitu 31,52 persen. Selanjutnya adalah Papua Barat yaitu 27,14 persen. Berdasarkan besar persentase tersebut ternyata nilai persentase terbesar mengelompok di wilayah Kawasan Timur Indonesia (KTI). Masih rendahnya tingkat infrastruktur dan aksesibilitas di KTI menjadi salah satu alasan masih banyaknya persentase penduduk yang dibawah garis kemiskinan. Agar tidak menimbulkan gejolak penduduk miskin sebaiknya dengan menjaga stabilitas bahan makanan yang harus tetap dijaga agar dapat sedikit demi sedikit status keluarganya untuk keluar dari jurang kemiskinan. Persentase terkecil untuk persentase penduduk dibawah garis kemiskinan dimiliki oleh Provinsi Bali yaitu sebesar 4,49 persen. Disusul oleh provinsi Kalimantan Selatan sebesar 4,76 persen, Kepulauan Bangka Belitung sebesar 5,25 persen, Bnaten sebesar 5,89 persen dan Kalimantan Tengah sebesar 6,23 persen.

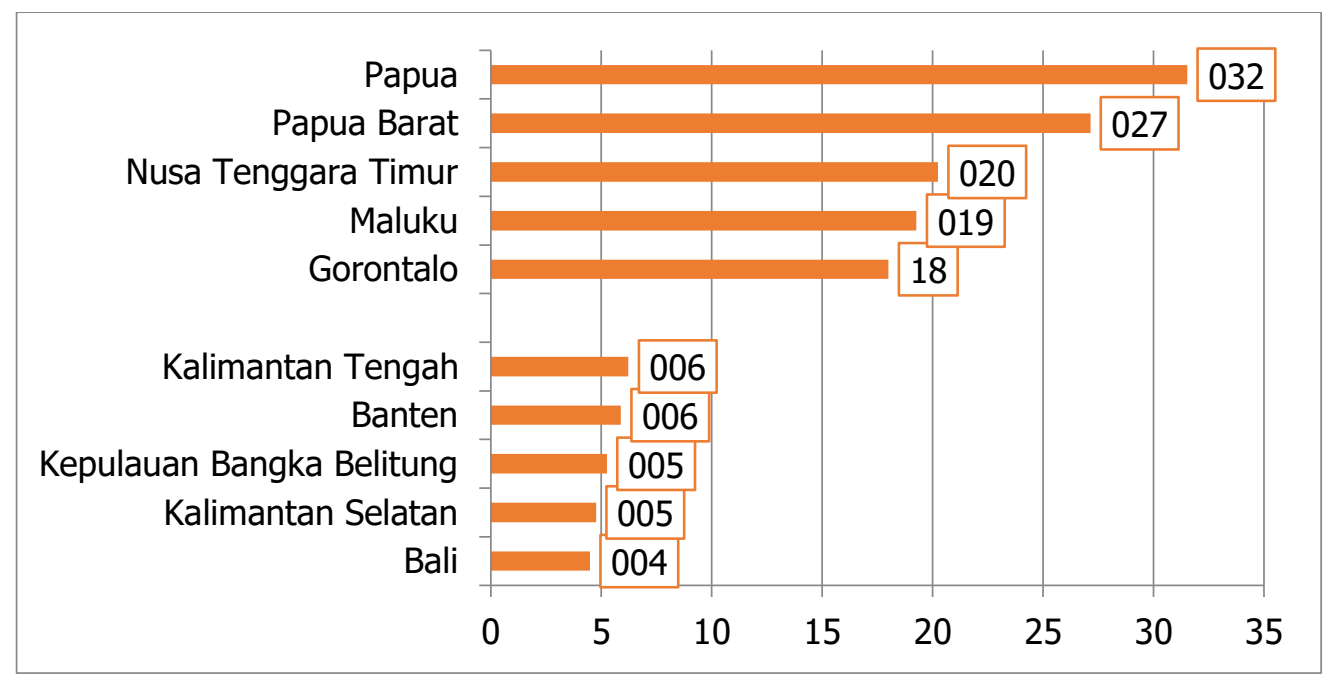

Gambar 2. Persentase penduduk dibawah garis kemiskinan untuk lima provinsi terbesar dan terkecil, Tahun 2015

\section{Peta Klasifikasi Prioritas kerawanan Pangan Kabupaten/Kota di Indonesia}

Prioritas rendah atau daerah berwarna hijau terkonsentrasi di Pulau Jawa. Kemudian disusul Pulau Sumatera dan beberapa wilayah di Pulau Sulawesi yang menunjukkan prioritas terendah setelah Pulau 
Jawa. Sebaliknya, wilayah dengan prioritas kerawanan pangan yang tinggi adalah Pulau Papua dengan diperlihatkannya warna yang paling oranye dibandingkan wilayah lainnya. Hal tersebut disayangkan karena berdasarkan hasil tersebut diperoleh fakta bahwa efisiensi usaha ketahanan pangan belum merata secara sempurna dan hanya berkonsentrasi di Pulau Jawa. Keterangan warna menunjukkan klasifikasi prioritas kerawanan pangan dari setiap daerah. Semakin hijau warna maka semakin rendah prioritas kerawanan pangan provinsi tersebut.

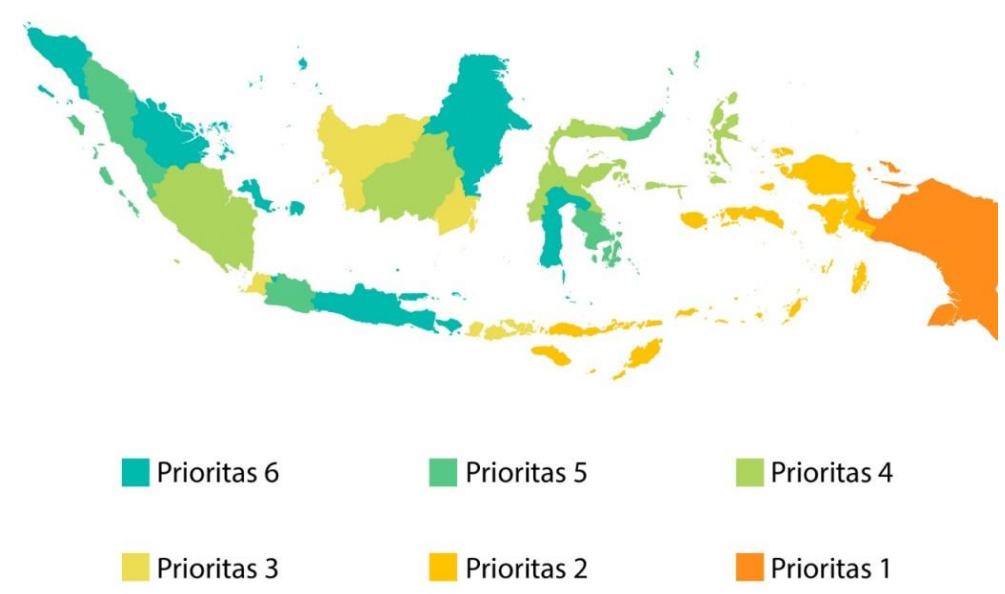

Gambar 3. Persentase penduduk dibawah garis kemiskinan untuk lima provinsi terbesar dan terkecil, Tahun 2015.

\section{Pembangunan Model Back Propagation Neural Network}

1. Preprocessing Data

Sebelum membangun model kita perlu mengenali karakteristik dari data yang telah didapatkan, maka dari itu perlu dilakukan preprocessing data untuk mempersiapkan data sampai benar-benar dapat digunakan untuk membangun model. Pada data mengenai delapan indicator kerawanan pangan kabupaten/kota di Indonesia ini tidak terdapat missing value ataupun kesalahan dalam inputasi data. Namun, setiap indikator memiliki satuan yang berbeda sehingga perlu dilakukan normalisasi/standardisasi. Data yang telah distandardisasi ini selanjutnya akan digunakan sebagai training dataset untuk membangun model.

2. Training Model

Tahapan selanjutnya adalah membangun model dengan algoritma Back Propagation Neural Network. Kemudian dilakukan training mode/ dengan architecture yang terdiri dari 5 (lima) hidden layer dengan 1000 epoch dan learning rate 0.5. Model tersebut dilatih training dengan menggunakan dataset yang telah dipersiapkan sebelumnya.

3. Evaluating Model

Setelah dilakukan training, model dievaluasi berdasarkan akurasi selama training. Ukuran evaluasi model diukur menggunakan cross validation score. Model dari hasil training yang telah dilakukan memilki akurasi sebesar 0.902 hal ini mengindikasikan bahwa model yang dibangun sangat baik untuk memprediksi kelompok prioritas kerawanan pangan berdasarkan indikator-indikator yng telah ditetapkan.

4. Preprocessing Data

Selain dapat memprediksi kelompok prioritas kerawanan pangan untuk setiap kabupaten kota di Indonesia, model ini pun dapat digunakan untuk memprediksi kelompok prioritas kerawanan pangan di setiap provinsi dengan menggunakan indicator yang sama.

Tabel 2. Hasil prediksi klasifikasi prioritas kerawanan pangan setiap provinsi di Indonesia.

\begin{tabular}{|c|c|}
\hline Provinsi & Kelompok Prioritas \\
\hline$(1)$ & $(2)$ \\
\hline Aceh & Prioritas 5 \\
\hline Sumatera Utara & Prioritas 5 \\
\hline
\end{tabular}




\begin{tabular}{|c|c|}
\hline Sumatera Barat & Prioritas 5 \\
\hline$\ldots$ & $\ldots$ \\
\hline Maluku Utara & Prioritas 4 \\
\hline Papua Barat & Prioritas 2 \\
\hline Papua & Prioritas 1 \\
\hline
\end{tabular}

\section{Rancangan Arsitektur Sistem}

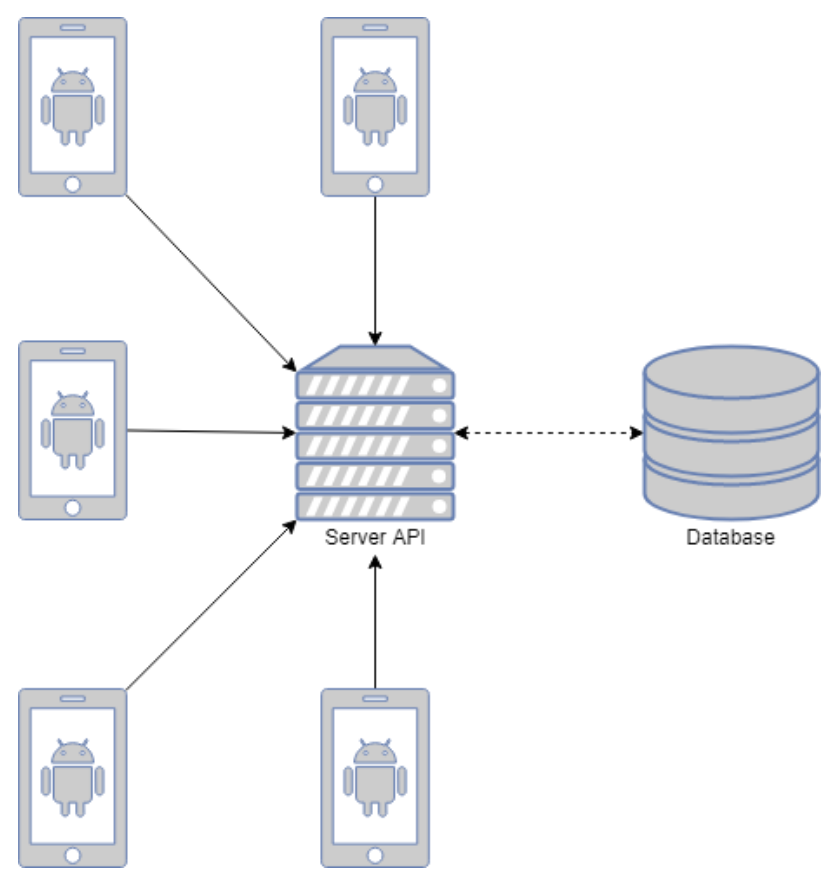

Gambar 4. Rancangan arsitektur sistem

Arsitektur sistem di atas merupakan arus pengumpulan data ketahanan pangan. Setiap titik dari smartphone android akan diberikan kepada setiap lembaga yang menyediakan data dari setiap indikator ketersediaan pangan. Lembaga tersebut adalah Badan Pusat Statistik, Badan Ketahanan Pangan, Dinas Kehutanan, Departemen Pekerjaan Umum dan Badan Meteorologi, Klimatologi dan Geofisika. Dengan sistem ini, data ketahanan pangan Indonesia akan terkumpul dengan lebih efektif dan efisien. Server API dan Database akan dikelola oleh Badan Ketahanan Pangan.

\section{Aplikasi}

Membangun aplikasi deteksi ketahanan pangan ini dapat membantu mengefektifkan penyebaran informasi dan pengetahuan ketahanan pangan setiap daerah serta faktor-faktor yang mempengaruhi ketahanan pangan. Aplikasi android lebih sering digunakan oleh masyarakat luas sehingga bisa menjadi sarana yang lebih efektif dalam menyebarluaskan informasi dan pengetahuan mengenai ketahanan pangan.

Aplikasi ini memiliki dua user leve/yaitu masyarakat umum dan lembaga terkait. Adapun user level pertama yaitu masyarakat umum akan mendapat fitur visualisasi data ketahanan pangan Indonesia per daerah. User leve/ lainnya yaitu untuk lembaga yang menyediakan data indikator-indikator ketahanan pangan sehingga akan ada tambahan fitur input data.

\section{Tampilan Aplikasi}

1. Tampilan Halaman Menu Input

Antarmuka halaman menu input ini menampilkan form untuk menginput data ketahanan pangan suatu daerah. Pengguna diminta untuk mengisi form, lalu diminta untuk menekan tombol 'input'. 
Form menggunakan sistem validasi sehingga apabila terdapat isian yang tidak sesuai maka akan langsung memunculkan pesan peringatan. Menu ini hanya akan muncul untuk user leve/lembaga. Setiap lembaga menginput data yang berbeda-beda.

2. Tampilan Halaman Menu Peta

Antarmuka halaman menu peta menampilkan peta Indonesia dengan perbedaan warna berdasarkan prioritas kerawanan pangan. Peta ini merupakan visualisasi dari hasil klasifikasi dari model.

3. Tampilan Halaman Menu List

Antarmuka halaman menu list menampilkan daftar provinsi di Indonesia. Ketika salah satu provinsi dipilih, akan memunculkan daftar kabupaten atau kota. Lalu, setelah salah satu kabupaten atau kota itu dipilih, akan memunculkan informasi dari ketahanan pangan suatu kabupaten/kota.
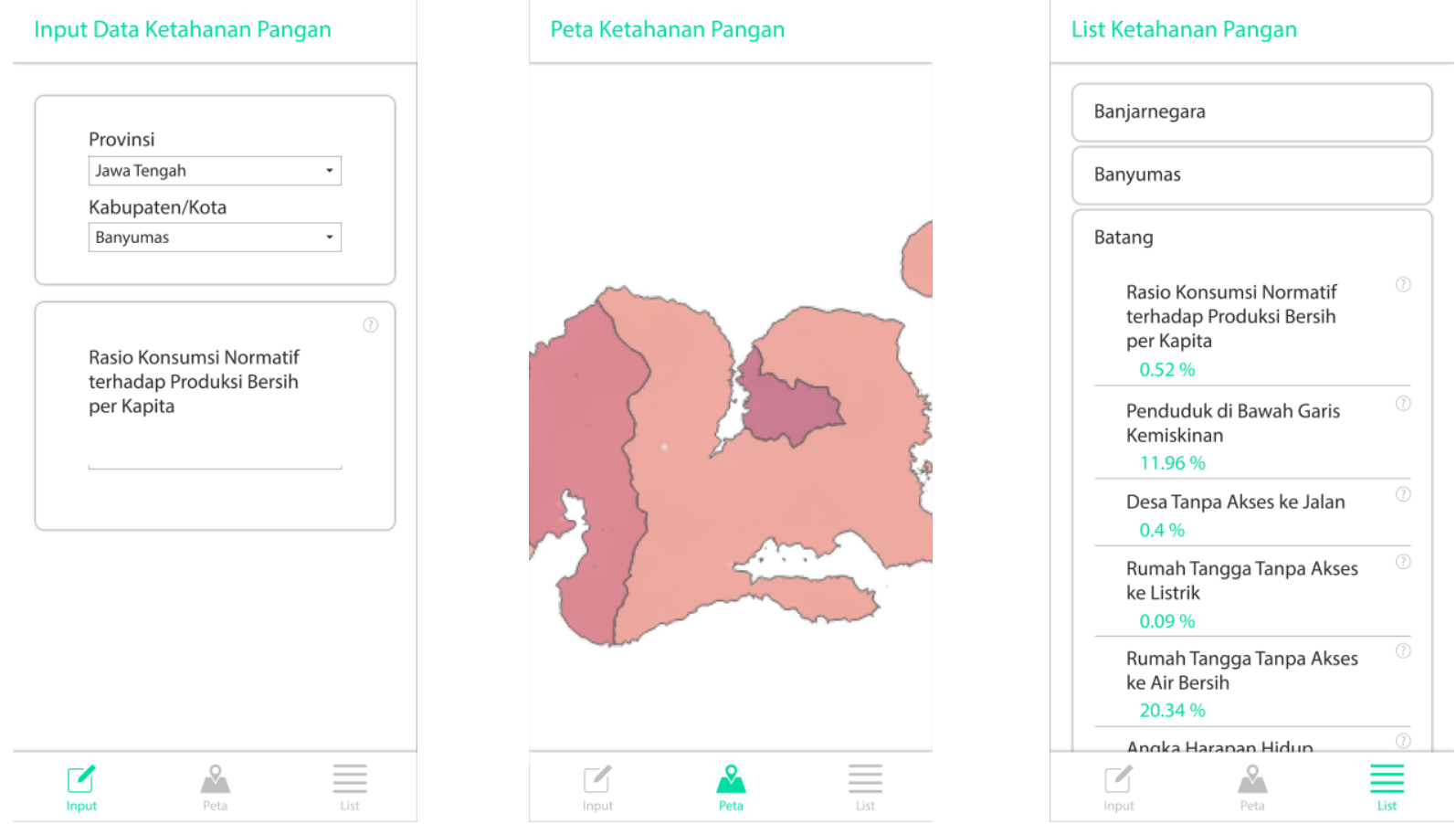

Gambar 3. Halaman menu (atas), deteksi (kiri), peta (tengah), list (kanan).

\section{Struktur Navigasi}

Struktur navigasi adalah urutan alur informasi dari suatu aplikasi. Menggunakan struktur navigasi yang tepat maka suatu aplikasi mempunyai suatu pedoman dan arah informasi yang jelas. Struktur Navigasi yang digunakan pada aplikasi ini adalah Hierarchial Model. 


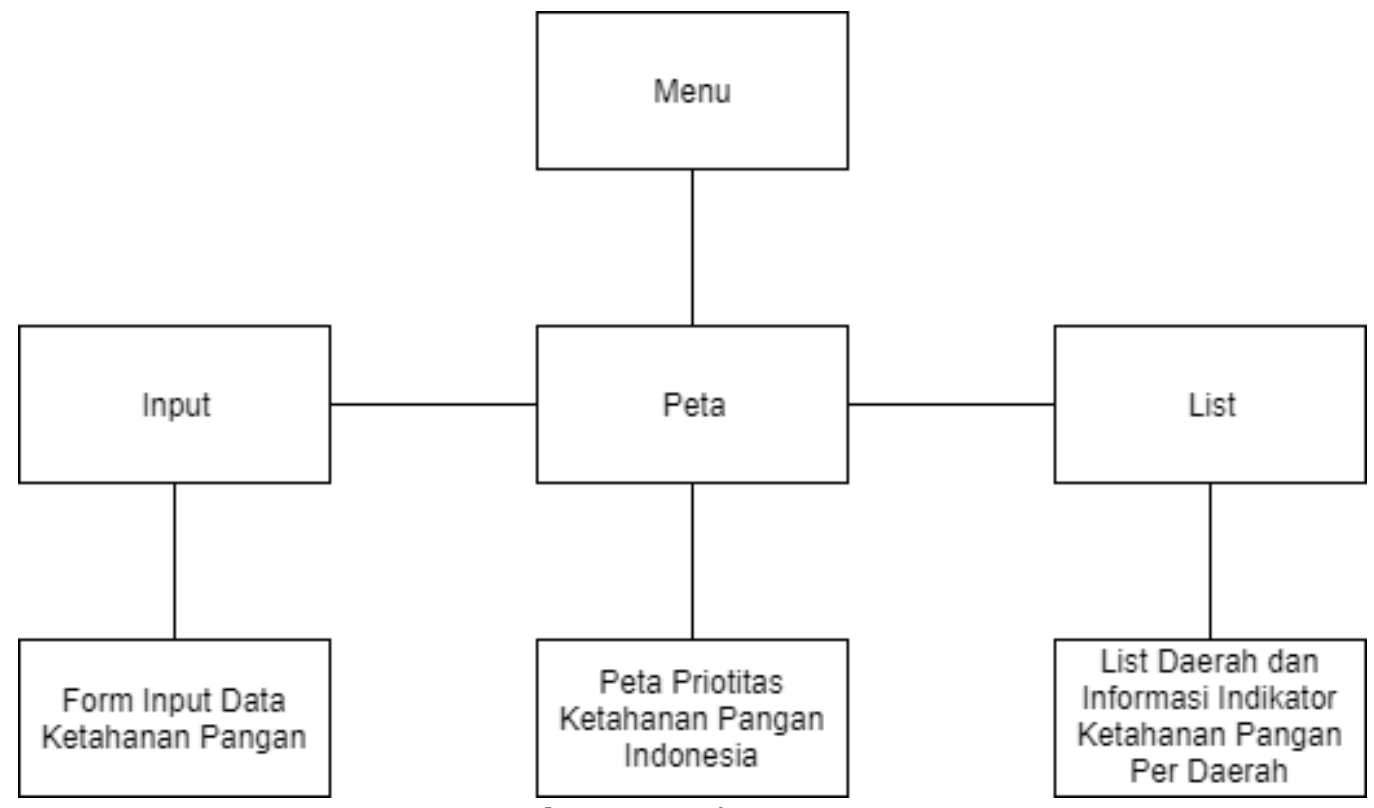

Gambar 5. Struktur navigasi.

\section{KESIMPULAN}

Permasalahan kelaparan dan kekurangan gizi yang tertuang dalam tujuan ke-2 (dua) SDGs merupakan permasalahan yang selalu disorot sehingga setiap negara dituntut untuk lebih konsepsional dan menggunakan data ilmiah dalam menyusun kebijakan dan program gizi khususnya di Indonesia. Indonesia bahkan menjadikan ketahanan pangan menjadi prioritas utama pembangunan. Namun, kebijakan yang berkaitan tentang ketahanan panggan di Indonesia belum didukung oleh sistem yang dibangun untuk mendeteksi terjadinya penurunan ketahanan pangan di suatu daerah.

Salah satu indikator ketersediaan pangan yang digunakan dalam analisis ketahanan pangan adalah rasio konsumsi normatif terhadap produksi bersih per kapita yang nilainya sangat timpang antar provinsi. Jumlah penduduk miskin di Indonesia juga menunjukkan kecenderungan mengelompok di Kawasan Timur Indonesia (KTI). Prioritas rendah atau daerah berwarna hijau terkonsentrasi di Pulau Jawa, Pulau Sumatera dan beberapa wilayah di Pulau Sulawesi. Sebaliknya, wilayah dengan prioritas kerawanan pangan yang tinggi adalah Pulau Papua dengan diperlihatkannya warna yang paling oranye dibandingkan wilayah lainnya.

Selanjutnya, setelah melakukan serangkaian proses pembangunan model back propagation neural network diperoleh model yang dapat digunakan untuk memprediksi kelompok prioritas kerawanan pangan di setiap provinsi dengan menggunakan indikator yang sama. Tingkat akurasi model tersebut sebesar 0,90 yang mengindikasikan model yang dibangun sangat baik untuk memprediksi kelompok prioritas kerawanan pangan berdasarkan indikator-indikator yang telah ditetapkan. Akhirnya, implementasi selanjutnya adalah membangun sistem deteksi ketahanan pangan yang terdiri dari pengumpulan data dan penggambaran atau visualisasi kondisi ketahanan pangan setiap daerah sehingga dapat membantu mengefektifkan penyebaran informasi dan pengetahuan mengenai ketahanan pangan setiap daerah serta faktor-faktor yang mempengaruhi ketahanan pangan. Aplikasi android lebih sering digunakan oleh masyarakat luas sehingga bisa menjadi sarana yang lebih efektif dalam menyebarluaskan informasi dan pengetahuan mengenai ketahanan pangan.

\section{DAFTAR PUSTAKA}

Dewan Ketahanan Pangan. (2005). Peta Kerawanan Pangan Indonesia A Food Insecurity Atlas of Indonesia. Jakarta: Dewan Ketahanan Pangan.

(2015). Food Security and Vulnerability Atlas of Indonesia 2015. Jakarta: Dewan Ketahanan Pangan.

Food and Agriculture Organization of United Nations. (2010). The State of Food Insecurity in the World. Roma: Publishing Policy and Support Branch.

Kemenko PMK. (2012). Kerangka kebijakan Gerakan Sadar Gizi dalam Rangka Seribu Hari Pertama Kehidupan (1.000 HPK). Jakarta: Kementerian Koordinator Pembangunan Manusia dan Kebudayaan Republik Indonesia. 
Kementrian PPN dan Bappenas. (2017). Arahan Terkait Pencapaian Pelaksanaan Tujuan Pembangunan Berkelanjutan. 10 Agustus 2019. http://www.iaiglobal.or.id/v03/files/file_publikasi/Keynote\%20bmb.pdf.

Permatasari, Deby Lolita dan Vita Ratnasari. (2016). Pemodelan Ketahanan Pangan di Indonesia dengan Pendekatan Regresi Probit Ordinal. 10 Agustus 2019. https://media.neliti.com/media/publications/132085-ID-pemodelan-ketahananpangan-di-indonesia.pdf.

Purwantini, Tri Bastuti. (2014). Pendekatan Rawan Pangan dan Gizi: Besaran, Karakteristik, dan Penyebabnya. 10 Agustus 2019. https://bit.ly/33hrIOy.

RI (Republik Indonesia). (2012). Undang-Undang No. 18 Tahun 2012 tentang Pangan. Lembaran Negara RI Tahun 2012 , No. 227. Sekretariat Negara. Jakarta.

Sampurno, Rizky Mulya dan Kudang Boro Seminar. (2017). Aplikasi Jaringan Syaraf Tiruan Pada Sistem Deteksi Dini untuk Manajemen Krisis Pangan. Jurnal Teknotan, 11 (1), 68-76.

Suryanto (2017). Data Mining Untuk Klasifikasi dan Klasterisasi Data. Bandung: Informatika Bandung.

Yoshua Bengio, Yves Grandvalet. (2004). No Unbiased Estimator of the Variance of K-Fold Cross-Validation. 10 Agustus 2019. http://www.jmlr.org/papers/volume5/grandvalet04a/-grandvalet04a.pdf

Widayaningsih, Neni. (2012). Ketahanan Pangan pada Rumah Tangga Miskin (Perbandingan Kasus di Perdesaan dan Perkotaan Kab. Banyumas). 10 Agustus 2019. https://bit.ly/2Krs8dG.

\section{LAMPIRAN}

Lampiran 1. Sepuluh data pertama dari delapan indikator klasifikasi prioritas kerawanan pangan kabupaten/kota seluruh Indonesia

\begin{tabular}{rrrrrrrrrr}
\multicolumn{2}{r}{ prior } & ncpr & pov & road & elec & water & life & flit & health \\
\hline $\mathbf{0}$ & 3 & 0.66 & 20.57 & 5.80 & 4.28 & 43.72 & 63.32 & 0.37 & 0.00 \\
$\mathbf{1}$ & 3 & 2.86 & 18.73 & 9.17 & 5.22 & 44.40 & 65.58 & 8.85 & 1.67 \\
$\mathbf{2}$ & 5 & 0.36 & 13.44 & 6.54 & 2.97 & 33.76 & 67.54 & 7.91 & 2.69 \\
3 & 6 & 0.13 & 14.39 & 4.68 & 2.38 & 27.69 & 69.69 & 3.45 & 0.52 \\
4 & 4 & 0.34 & 16.59 & 9.34 & 5.55 & 39.53 & 70.26 & 3.59 & 0.78 \\
5 & 5 & 1.10 & 17.76 & 4.07 & 2.62 & 33.51 & 70.26 & 1.16 & 2.71 \\
6 & 5 & 0.60 & 23.70 & 10.59 & 3.49 & 37.10 & 70.55 & 5.05 & 6.54 \\
7 & 4 & 0.37 & 16.88 & 0.17 & 2.91 & 43.91 & 71.17 & 4.89 & 1.32 \\
8 & 5 & 0.35 & 21.12 & 1.50 & 1.73 & 29.85 & 70.34 & 7.94 & 0.55 \\
9 & 5 & 0.42 & 17.65 & 6.08 & 3.72 & 28.90 & 72.63 & 2.23 & 0.49 \\
10 & 5 & 0.34 & 20.34 & 6.92 & 3.93 & 33.61 & 70.26 & 4.54 & 3.05
\end{tabular}


Lampiran 2. Hasil prediksi klasifikasi prioritas kerawanan pangan di setiap provinsi di Indonesia

\begin{tabular}{|c|c|}
\hline Provinsi & Kelompok Prioritas \\
\hline (1) & (2) \\
\hline Aceh & Prioritas 5 \\
\hline Sumatera Utara & Prioritas 5 \\
\hline Sumatera Barat & Prioritas 5 \\
\hline Riau & Prioritas 6 \\
\hline Jambi & Prioritas 4 \\
\hline Sumatera Selatan & Prioritas 4 \\
\hline Bengkulu & Prioritas 4 \\
\hline Lampung & Prioritas 4 \\
\hline Kepulauan Bangka Belitung & Prioritas 6 \\
\hline Kepulauan Riau & Prioritas 6 \\
\hline Jawa Barat & Prioritas 5 \\
\hline Jawa Tengah & Prioritas 6 \\
\hline DI. Yogyakarta & Prioritas 6 \\
\hline Jawa Timur & Prioritas 6 \\
\hline Banten & Prioritas 3 \\
\hline Bali & Prioritas 6 \\
\hline Nusa Tenggara Barat & Prioritas 3 \\
\hline Nusa Tenggara Timur & Prioritas 2 \\
\hline Kalimantan Barat & Prioritas 3 \\
\hline Kalimantan Tengah & Prioritas 4 \\
\hline Kalimantan Selatan & Prioritas 3 \\
\hline Kalimantan Timur & Prioritas 6 \\
\hline Sulawesi Utara & Prioritas 5 \\
\hline Sulawesi Tengah & Prioritas 4 \\
\hline Sulawesi Selatan & Prioritas 6 \\
\hline Sulawesi Tenggara & Prioritas 5 \\
\hline Gorontalo & Prioritas 4 \\
\hline Sulawesi Barat & Prioritas 4 \\
\hline Maluku & Prioritas 2 \\
\hline Maluku Utara & Prioritas 4 \\
\hline Papua Barat & Prioritas 2 \\
\hline Papua & Prioritas 1 \\
\hline
\end{tabular}

